\title{
Japanese style management in eras of change: new management model
}

\author{
Masao Hirasaka ${ }^{1}$ (D) $\cdot$ Yasuo Kusaka $^{2} \cdot \operatorname{Jim}$ Brogan $^{2}$ \\ Received: 7 October 2020 / Accepted: 11 May 2021 / Published online: 28 May 2021 \\ (c) The Author(s), under exclusive licence to Springer Nature Switzerland AG 2021
}

\begin{abstract}
Changes in technologies and markets are issues for all global companies. Japanese companies also face difficulties in eras of change. There is a need for paradigm shifts in management style. This paper will look at four case studies of major global companies and analyze the concept of the hybrid approach. It looks at how western and Japanese ways of thinking and methods can be combined to create a new model. The new Japanese model proposes a basic framework on which customization and improvement can be carried out.
\end{abstract}

Keywords Leadership · Corporate management · Corporate culture

\section{Introduction}

Japanese companies have grown steadily by technological innovations and production management systems. But, IMD World Competitiveness Center (IMDWCC) brought down Japan competitiveness from 1st in 1990 to 34th in 2020 (IMD 2020). The decline in the competitiveness of Japanese companies in the last 30 years demonstrates a need for changes in management strategies (Keizer et al. 2012; Endo et al. 2015). The causes of this decline are, in large part, delays in responding to open innovation and losing technological superiority due to fierce competition between the original company and subsequent competing companies (Chesbrough 2013, 2014). Moreover, Japanese companies delayed shifting to an added customer value creation model from one focused on manufacturing. Japanese companies thought that prioritizing high technology would be enough to create customer value and be profitable. Japanese companies have invested more in $R \& D$ than companies in other developed countries in the world, but these investments have not translated

Masao Hirasaka

m.hiraaka@spsj.or.jp

1 The Society of Polymer Science, Japan, 3-10-9 Irifune Chuo-ku, Tokyo, Japan

2 Dokkyo University, Soka, Saitama, Japan 
into superior corporate performance (Shikata et al. 2019). The current state of management in Japan, Japanese business efficiency remains unimproved as shown in IMD's 2020 World Competitiveness Ranking; Management Practices is 62th, Attitudes and Values is 56th and Productivity \& Efficiency is 55th (IMD 2020).

Now, urgent issues facing corporate management are how to deal with information technologies, such as IoT and Industry 5.0 (Aslam et al. 2020), Artificial Intelligence and machine learning (Wang and Siau 2019; Canhoto and Clear 2020), as well as the ways in which globalization has affected the rapid economic growth of China and developing countries. Moreover, there are big issues about COVID-19. Studies on COVID-19 impact such as Japanese governments' responses (DeWit et al. 2020), Organization design (Foss 2020) and reshoring after COVID-19 (Barbieri et al. 2020) were reported.

Business leaders with a new approach are vital under rapid environmental change. In recent decades, business leaders have not been able to respond in the face of environmental changes and complicated market structures with appropriate management decision-making (Tongur and Engwall 2014). Lack of abilities of business leader may depend on a human resources development programs. Japanese companies do have human resources development programs in place, but these do not focus on nurturing business leaders or entrepreneurship.

The authors have previously researched management and decision-making in response to external environmental changes (Kusaka and Hirasaka 2011, 2013, $2014 \mathrm{a}, \mathrm{b})$. In these papers, the importance of "the hybrid approach to Japanese decision-making" was stressed. The hybrid approach means that heterogeneous things or conflicting concepts being merged to create new ones. Hybrid vehicles is typical example, which have developed using heterogeneous technologies. Biomimetics is also fusion of biology and mimetic-engineering (Bhushan 2009). Focusing on management, hybrid teams and hybrid organization were studied (Earley and Mosakowski 2000; Maine et al. 2020).

Historically, Japan has absorbed Chinese culture and, since the Meiji era, western culture. It was good for Japan to positively absorb necessary different cultures while keeping in harmony with Japanese traits. Japanese companies, therefore, should create a new management style while maintaining Japan's sensitivities and strengths, correcting the weaknesses in Japanese systems, and actively absorbing the good points of western companies. This new management style would strengthen Japanese companies in the new economic era. The authors previously proposed the importance of theoretical hybrid management in decision-making (Kusaka and Hirasaka 2011) in conjunction with the importance of learning from actual comparative cases of successful and failed companies. Key factors affecting paradigm shift were examined and causal relationships were assessed, through case studies (Kusaka and Hirasaka 2016a, b).

COVID-19 will make big impacts in corporate managements and companies have no experience in dealing with pandemics like never before. However, it is a fact that Japanese companies have survived the crisis so far by taking advantage of the characteristics of Japanese style management. The authors believe that acquiring knowledge from the lessons learned from success and failure will be a great guideline for future management. 
This study aims to provide Japanese companies, that have not been able to break away from their entrenched closed innovation and have not been successful in structural reform, with a new management model for structural reform and innovation which can respond to environmental changes. The new model may not be effective for all companies, as it depends on the individual company's situation, such as the industrial field, competitive situation, technological trends, corporate culture, management resources and decision-making systems. However, the authors believe that the new model proposes a basic framework in which customizing and improving can be carried out by adding or deleting elements peculiar to the individual company. In particular, technology companies need to continuously change their management models to respond to changes in technology and markets, and in order to respond to major business changes due to COVID-19, the authors think this proposed model will be helpful.

\section{Japanese management practices and issues}

Japanese ways of thinking and company management systems also influence strategy formulation. For example, the Japanese emphasis on subtlety, commitment, cooperation, honesty and hospitality, have positive effects. On the other hand, characteristics such as discriminating between inner and outer groups, introversion, the need for collective decision-making and, to some western ways of thinking, a kind of illogical or irrational approach, have negative effects. Such Japanese characteristics have been linked to the excellence of Japanese manufacturing products, product development and high levels of customer service (Nisbett 2003; Ogasawara and Shigehisa 2009; Shimura 2009; Takata 2016).

There is a difference in entrepreneurship. In the United States, innovation is often promoted by venture companies not by large companies. Entrepreneurs encourage risky innovation in companies with high potential returns and have liberal and positive attitudes to failure, reasoning that the knowledge gained from a failure can, eventually, lead to future success. In addition, venture capital companies that financially support venture companies, are much more successful than in Japan. Big companies also play a role in support promising venture companies. As a result, the US innovation ecosystem is composed of venture companies, venture capital, big enterprises that pursue short-term profits, big enterprises that invest in promising venture companies as a minor part of their strategies and banks that financially support the big enterprises.

On the other hand, in Japan, entrepreneurship may occur in existing corporations and may be driven by the existence of high levels of loyalty within Japanese corporations (similar to families) (Gantenbein et al. 2019). Japanese new product development includes the strength of the disciplined problem solving stream of research by explicitly considering how Japanese cultural tendencies (e.g., high uncertainty avoidance) may be intertwined with the organization of work and selection of problem-solving strategies (Song and Montoya-Weiss 2001).

In eras when external and internal environmental factors change rapidly, it is necessary for Japanese management to grasp the important issues from global and 
systematic viewpoints. Japanese companies need to foster an understanding of the international environment and diverse values and cultures. Other factors are the characteristics of technological innovation (which includes the issues of speed of technological development), more diversification to better suit customer needs, the integration of complex technologies and large scale investment for technological development. One important external environmental factor is globalization.

Bases on management perspective, the Innovation 100 Committee (2016) points out that there are five major issues in the management of Japanese companies:

Issue 1: They are not able to switch from the traditional model.

Issue 2: There is too much focus on the short-term results of existing business.

Issue 3: They do not understand the essential needs of customers.

Issue 4: Almost none of the ideas proposed from the front line of business are acted upon.

Issue 5: There is too much reliance on internal resources.

These issues include that top-down decision-making and bottom-up decisionmaking have not been integrated in Japanese companies. In other words, the issue is how to lead the strengths of Japanese companies through the fusion of management and employees. Also, there is a lack of crisis management and ambition due to the stable thinking of Japanese.

There are many things that should be changed in the Japanese company way of thinking and system of management, such as actively incorporating the advantages of western countries, however, maintaining basic Japanese strength is also essential. The emphasis on social mission and corporate philosophy should continue to be incorporated into the new Japanese style management. Japanese managers need to create a unique style for Japanese companies, appropriate to new business environments and competitive conditions.

There are a few research cases on Japanese style management innovation. There are research on human resource management (Morris et al. 2019) and study on comparison the management characteristics of U.S., German, and Japanese manufacturing corporations (Min et al. 2019). However, study of Japanese management based on successes and failures cases has not been done. The authors have focused on case studies and explore a new Japanese management model.

In Japan, there are companies that have responded to environmental changes appropriately and companies that have failed to respond. This paper focusses on four cases: Fujifilm, Kodak, Nissan Motors and Sharp. Fujifilm and Kodak faced rapid fall in photo film demand due to the appearance of digital cameras. Fujifilm survived the crisis of technology change and Kodak went bankrupt. Nissan Motors succeeds in rebuilding its financial situation through management innovation. On the other hand, Sharp faced a financial crisis due to a misunderstanding of the LCD business in the future. There are several articles and books on the management of Fujifilm (Tohoku University Management Group 2008; The Economist 2012a; Komori 2013; Shibata et al. 2019a, b) and Kodak (Deutsch 2008; The Economist 2012b; Moon 2019). There are also reports on the management of Nissan Motors (Ghosn 2002; NHK 2005; Yoshino and Egawa 2010; Ikegami et al. 2017) and Sharp (Nakada 2015; Nikkei Business 2015; Sharp Company 2015). 
There are few comparative studies on the successes and failures of Japanese companies and western companies. The authors investigated how they dealt with the crisis from newspapers, repots and books. And we, have looked at two such comparisons, one of two companies in the same industry and one of two companies in different industries, in the hope of distilling the essences of success and failure.

\section{Successes and failures}

\section{Fujifilm and Kodak}

In the 1990s, there was oligopolistic control of the market for silver halide photographic film, formed by four companies: Kodak in the United States, Agfa in Germany, Fujifilm in Japan and Konica in Japan. Kodak had established a worldwide brand in the field of photography with advanced technology and innovative marketing. Though the appearance of digital cameras posed a major threat to the existing markets, Kodak failed to respond effectively and went into Chapter 11 of bankruptcy in January of 2012. Meanwhile, Fujifilm, which was pursuing Kodak with the goal of "catch up with Kodak", faced a similar threat from the new technology but managed to emerge intact. However, Fujifilm's response was different to Kodak's. Fujifilm had forecast the arrival of the new technology, promoted diversification into related businesses, and carried out structural reform. As a result, Fujifilm improved their business situation.

Due to its superior technologies and management skills, Kodak must have felt optimistic that the company could fully absorb the impact of the digitalization era. It stayed with its existing business model and failed to sufficiently incorporate the new technology into its business model.

Fujifilm realized that it would not ever be able to break its position as world number two by maintaining the traditional management style. The company considered the change to digitization a great opportunity and planned to make a leap by improving R\&D capabilities and management skills. It acted positively to pursue a corporate culture change towards innovation.

The differences in approaches between Fujifilm and Kodak to digital innovation are clearly shown in Table 1. Corporate cultures develop over many years. Kodak had a negative and closed environment to change, Fujifilm was more positive and open to such changes. The basic attitudes toward change were largely influenced by the strengths and weaknesses of each company and its corporate culture.

The success or failure of a paradigm shift relates to basic attitudes toward change throughout the whole organization. In other words, it is difficult to achieve a paradigm shift unless top managers recognize their companies' strengths and weaknesses and are willing and capable of changing corporate culture. Success and failure largely depended on whether the company had an active or passive response to paradigm shift.

Both Kodak and Fujifilm focused on technology and marketing. However, Kodak had used its marketing capabilities to build top brands in the declining market of photographic film. Fujifilm had tried to apply their photographic 
Table 1 Management differences between Fujifilm and Kodak

\begin{tabular}{lll}
\hline & Fujifilm & Kodak \\
\hline External environmental change & & \\
Technology & Appearance of digital cameras (digital technology) \\
Insight to environmental change & Responsive & Negative \\
Threat of new technology & Recognition & Lack of recognition \\
Company characteristics & & \\
Technology of photographic film & Follower & Leading position \\
Technology development & Various fields & Focus on photographic film \\
Marketing & 2nd position & Top brand \\
Corporate culture & Innovative & Stability oriented \\
& Emphasis on employees & Profit oriented \\
Leadership of CEO & Clear & Clear \\
Business model & Film supplier and camera manufac- & Film supplier \\
Reactions to changes & turer & \\
Digital technology & & Positive \\
Paradigm shift & Positive & Negative \\
Business strategy & Expansion into other business fields & Focus on existing business \\
Investment strategy & Short-term and sustainable profit & Short-term profit \\
\hline & & \\
\hline
\end{tabular}

technology to other related business areas and had built new technologies and markets portfolios. The company aimed at developing a worldwide business of different markets and diversified technologies.

Kodak was content in maintaining its position as the leading company in the photographic film industry. Fujifilm expected innovation in new technologies to create new markets. It tackled the changes with the corporate goal of "continuing to be a leading company in the twenty-first century".

The clear foresight of top management and the presence of leadership are vital factors in the success or failure in structural reform. Top managers must show a strong will towards company changes and commit to structural reform. Management strategy should be formulated under a clear corporate vision. It needs to recognize many factors in its industrial structure; the market position of the company, its differentiation from its competitors, the simultaneous development of technologies and markets, the balance between short-term profit (short-term perspective) and future expected profit (long-term perspective), harmony among strategies and continuity of strategies.

Kodak failed to adapt to the move to digitization, and Fujifilm responded appropriately to it, as shown in Table 1 . The authors would like to point out that the assessment of existing technologies implemented by Fujifilm through structural reform and the construction of new business domains were the basis for formulating its management strategies. 


\section{Nissan Motors and Sharp}

Nissan Motors, located in second position in the Japanese car market after Toyota, recorded a profit of 78 billion yen in March of 1997, supported by lively US demand and a depreciation of the yen, but the automobile sales volume had been declining over a number of years. In the automobile industry, globalization is a major trend. Automakers built their factories where they sell their products. Furthermore, low-cost production to increase profitability has become the mainstream.

Nissan Motors was forced to offer discounts due to the number of its older models with little differentiation in the range, too little investment in developing new better models (due to financial limitations), a low brand image, and weakness in the sales departments. As a result, Nissan Motors posted a loss of $¥ 14$ billion in March of 1998. Nissan faced a management crisis and made an alliance with Renault, and the new president, Carlos Ghosn, began structural reform.

Meanwhile Sharp, which had strong technology of liquid crystal displays (LCD), established competitive advantage in LCD devices. However, LCD TVs had been commoditized and development of LCD technology had rapidly processed. Moreover, South Korea and Taiwan have invested more aggressively in the LCD business than Japan. Sharp, which had a 223 billion yen deficit in 2015, announced a reform plan consisting of the sale of its headquarters building, introduction of the company system, and the voluntary retirement of 3,500 employees, which was about $15 \%$ of its 24,000 employees. Sharp, however, voluntarily abandoned its business reconstruction plan in 2015.

Nissan and Sharp are different industries, so it is somewhat difficult to compare, but differences in response to crises are clear, especially with respect to top management behavior. While recognizing the need for structural reform, until Ghosn was assigned as president, Nissan could not carry out the structural reform by itself. Top management took this management crisis seriously, abandoned its attempts at selfrevitalization, and decided to seek support from Renault. Ghosn, who had experience in cross-cultural management at local subsidiaries in each country, showed the leadership needed for the structural reform to revive Nissan. If Nissan had obsessed over its own self-revitalization plan, effective management analysis and aggressive structural reform might not have been achieved.

Ghosn first worked on building a form of collaboration between Renault and Nissan and built a management system whereby Renault executives could participate in the management of Nissan. He also organized Cross-Functional Teams (CFTs), consisting of Nissan employees, to solve important pending issues. This was a strategy to enhance the motivation of Nissan employees and maximize their abilities. Ghosn pointed out the lack of corporate vision which was a major weakness of Nissan's management, the necessity of top level commitment, the lack of profit orientation (including cost reduction) and the lack of customer orientation. He stressed that every employee should recognize the crisis situation facing the company and ordered CFTs to thoroughly pursue problem solving. He carried out reforms to the typical Japanese seniority system and implemented Western style personnel evaluation. He worked on consciousness reform aimed at getting out of conventional ways 
of thinking, including responsibility awareness and the importance of collaboration among departments.

To the employees, he clarified top management responsibility in decision-making (commitment) and convinced them of the importance of reform. Through internal departmental communication and external company collaboration, he tried to make understood the importance of 'co-creation' with diverse experts possessing different perspectives.

It has been pointed out that the slow speed of corporate decision-making is a weak point of Japanese companies. Ghosn set a time line for Nissan's structural reform and said that all top managers would resign if the plan were not achieved. Because of structural reforms with clearly defined terms, all Nissan employees worked hard to achieve their goals and made structural reforms successful.

Meanwhile, Sharp failed to recognize the rapid changes in the liquid crystal display market. The company attached too much importance to technology based on its own business principles and lacked the insight and analytical skill to see what was going on in the global market rather than in the galapagosized Japanese market. Sharp could not see that it was vital to switch its conventional management framework. It seemed to think that the business crisis could be easily avoided if the liquid crystal business increased with the developing smartphone market, and so did not grasp the necessity for a paradigm shift. There seems to have been no effort to adapt to the changing environment.

Sharp did not realize that there had been a paradigm shift in marketing from the old business mantra "If the company can make technically superior products, customers will buy them" to a philosophy of "Companies should make products customers desire". Sharp did not appear to understand the essence of management: that both technological development and marketing go hand in hand. The company lacked the marketing and management abilities that could have converted their excellent technology into viable business. Sharp's management crises and structural reform failures were caused by a management culture that prioritized technology.

Sharp had to thoroughly analyze what kind of new technologies and new businesses could be developed for a revival plan. However, poor insight into need for change became a fatal flaw in Sharp's structural reformation. Sharp's revival plan was like to ambiguous vision which not showed concrete path to take in the future. Then, the plan showed that voluntary retirement of 3500 employees, salary cuts for employees, sale of the head office building.

As shown in Table 2, there are other differences between Nissan and Sharp's response to managements. Although it is difficult to make a strict comparison between Nissan and Sharp because they are in different industries, the difference in their response to the important factors that determine structural reforms has become clear. At first glance, the differences in Nissan's and Sharp's attempts at structural reforms seems to be in contrast, but they actually arise from a response to common problems and weaknesses in Japanese companies. The reforms introduced at Nissan, by its new president Ghosn, is a case where a Japanese company could not initiate change by itself. Ghosn examined various cases of past failures from the perspective of an international manager with diverse experience and made improvements. This was not the situation at Sharp. In the cases of Nissan, the plans for structural reforms 


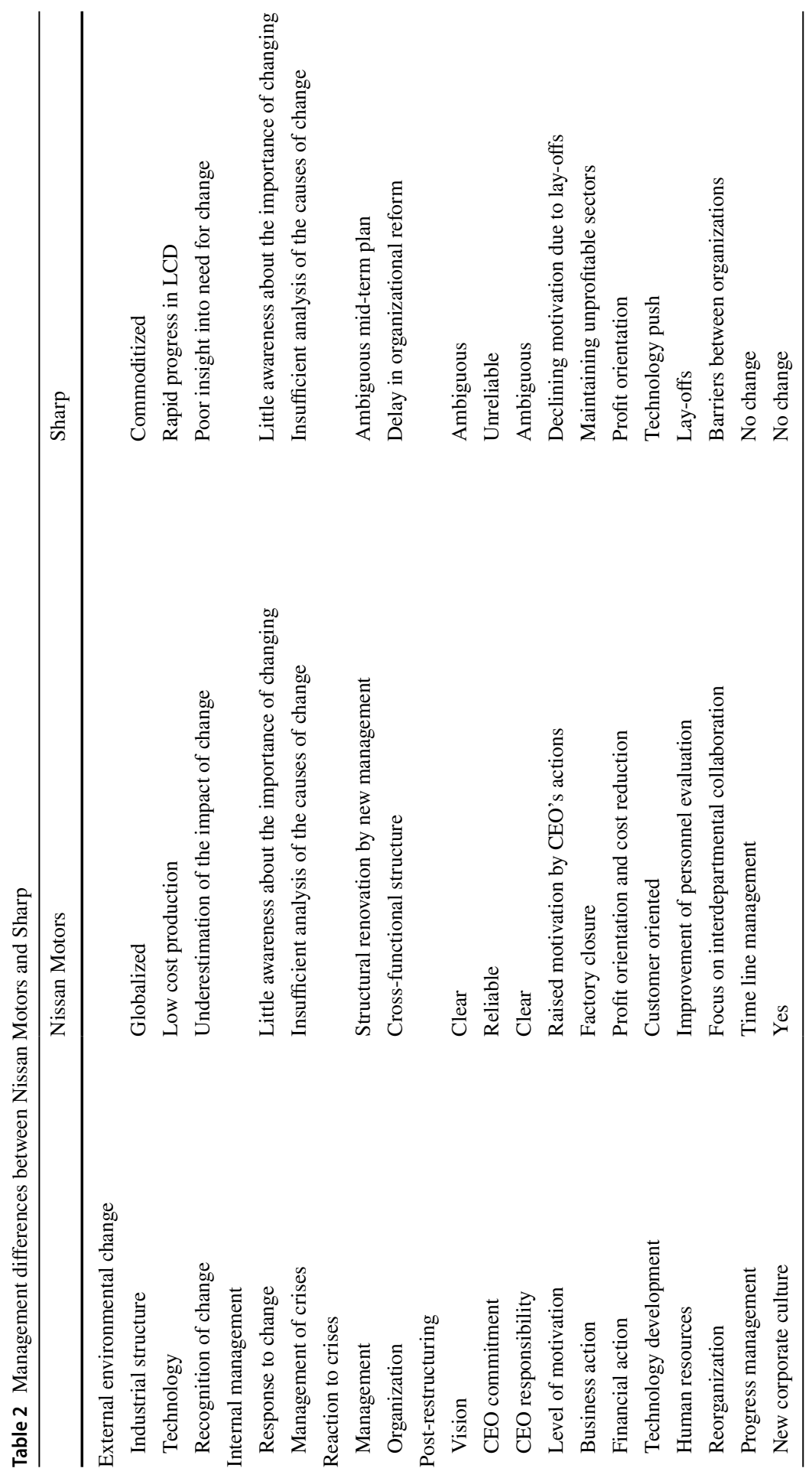

SN Business \& Economics 
under the leadership of their respective presidents were formulated and implemented. In contrast, in the case of Sharp, lack of leadership, lack of logical thinking and lack of problem solving skills in top management caused management crises.

\section{Knowledge creation from case studies}

\section{Differences in corporate management arising from differences in corporate culture}

According to Kagono (2012), American investors and shareholders consider companies (especially large companies) as investment targets, so if a company becomes unprofitable, they withdraw from the company. They expect profit-oriented management from CEOs and, because they have a strong position as shareholders, the CEOs pursue strategies geared towards short-term profit. The CEO of a company that produces a poor dividend is quickly removed by investors. Therefore, when the CEO changes, management policy and management strategy often change and tend to be inconsistent.

Pan and Zhou (2018) reported that the percentage of inside CEO successions is 92.7\% for Japan and $66.3 \%$ for the United States. In other words, whereas one-third of the new CEOs in the United States are hired from the external managerial labor market, the comparable percentage for Japan is merely $7.3 \%$. Because, Japanese firms rely on the role of internal labor markets in employee motivation where stable employment relationships and long-term career concerns are important. In the case of Nissan, it was rare case in Japan that Ghosn became CEO as external hiring.

\section{Attitudes to external environmental changes}

External environmental changes force companies to reform their structures. As the foundation for achieving structural reform, McGrath (2013) pointed out that in an era of change, it is important for companies to maintain a positive attitude to the challenges they face.

Many Japanese companies do not accurately analyze and recognize the serious impacts on their own companies of external environmental changes, or even if they do, they do not take countermeasures. This is partly due to their lack of problem solving skills such as analytical skills, planning skills and implementation skills. However, this failing is exacerbated by the failure of executive support staff to provide necessary, relevant data.

The Innovation 100 Committee in Japan (2016) reported, "The task of top management is not to carry out daily tasks, but to revitalize the organization with a strong determination by conveying its future vision to its people, both inside and outside of the company, and developing innovation". Top management needs a commitment to structural reform when faced with corporate crises and must take the responsibility to risky innovation. Ghosn clearly showed this commitment when he said that the top executives would resign if structural reforms were not successfully achieved. He 
also said that they should convince the employees of the need for reform and convey their strong determination to succeed. On the other hand, in the case of Sharp, the will with which top management carried out structural reform was inadequate, the responsibility for failure was ambiguous, and the top managers continued to reform in a haphazard way without clearly demonstrating their goals.

\section{Reactions to management crises}

The success or failure of structural reform depends on whether all employees can unite and tackle the management crisis faced. It is difficult to raise employees' motivation when reforms from top management are forced on workers. In the management reform at Nissan, CFT that promoted communication across divisions were utilized. CFT created a mechanism in which employees could implement reforms independently and carry out problem solving tasks under timeline management. In order to reform organizational and employee consciousness, Nissan improved the seniority-oriented personnel evaluation system, which is said to be the biggest weakness of traditional Japanese management, and created a mechanism in which employees themselves are involved in improvements. In addition, an action plan was formulated so that all employees could:

- Clarify the aims of structural reform and innovation taking responsibilities for actions.

- Ensure that all employees understand the will of top management.

- Achieve the goal of 'consciousness reforms' to break down traditional corporate culture and traditions.

Sharp's structural reform, in contrast, had been abstract with little, if any, trace of concrete planning. This could be attributed to a lack of problem solving skills, however, the main reason for failure was that top management did not actively commit to structural reform. In addition, management failed to raise employee motivation to implement reform and employees were often forced to pursue short-term goals. The repeated restructuring of the businesses also decreased corporate strength.

\section{Measures for structural reform}

In the structural reform of a company facing a management crisis, it is essential for top manager to take the initiative. Measures for the structural reform of Nissan were carried out under the powerful commitment of top management, and a proactive atmosphere to work on the reforms under timeline management was created among all employees. Ghosn's experience and know-how from intercultural management in Lebanon, Brazil, North America and France were used in the revival plan. The following actions were particularly important:

- Clarifying the corporate vision in an era of change. 
- Building mechanisms that enabled all employees to utilize collective power to work on reform.

- Conducting awareness reforms that helped employees change the corporate culture and customs.

- Ensuring that employees understand that the success or failure of the reform depends on the actions of all employees.

Such structural reform and efforts to innovate had to be carried out by top-down decision-making. On the other hand, it was also necessary for employees who were familiar with the work on site to have input and be committed to the reforms.

\section{The necessity for strong commitment to innovation by top management}

Innovation, which is usually born by chance in situations of chaos and uncertainty, is an extremely difficult problem for large enterprises with innovator's dilemma or walls between research unit and business unit. Innovation has to be tackled steadily over a long period, requiring investments in time and money that may impair profitability in the short term. As shown in the example of Kodak, which had a good reputation around the world but missed the wave of digitization and collapsed, companies that have sustained their profits over long periods by making continuous gradual improvements, may also go bankrupt suddenly. Innovation management, therefore, is an important aspect of top management.

Top management should clearly transmit innovation policy, for example by internal newsletters and speaking directly to middle managers and workers and show commitment by aggressive pursuit of their targets. It is important to select executives who can encourage and support employees in risky and stressful situations to be ambitious and develop their skills. It is not proper to select executives whose major focus is avoiding risk. Under its president Ghosn and with the infusion of his strategy into the organization, Nissan placed emphasis on the commitment of top management to reform.

\section{The fusion of TDD and BUD}

Hatou (2013) looked at the characteristics of US company decision-making styles in systematic, modular organizational management systems based on "top-down type decision-making (TDD)". He suggested that the characteristics come from the fact that the United States is a multi-ethnic, multi-religious and multi-lingual country, and that the society is composed of people with completely different values, lifestyles and levels of education. TDD was required as "a system of rules" that everyone could understand. It makes diverse groups of employees into an organization and achieves disciplined organizational management.

On the other hand, it is said that the characteristics of the decision-making process of Japanese companies are of "the bottom-up type decision-making (BUD) attaching importance to on-site judgement". The background behind it is the need to take 
consensus-oriented action rooted in the organizational culture, which respects the harmony and cooperation of different workers within the organizations.

In the 1980s BUD, companies were considered as "communities for their people" and it was management's responsibility to protect the company and nurture its employees. Middle managers at the front line were key players who had to improve operations and processes by accumulating skills in the organization and building competitive advantages. For Japanese companies, BUD has been the dominant management style for a long time. This style is rooted in the Japanese organizational culture that respects the harmony and cooperation of organizations.

The authors believe that harmony and cooperativeness can still be utilized in structural reform to the advantage of Japanese companies. However, in Japanese companies, it is the 'closed nature characteristic,' or 'Heisasei' in Japanese that maintains the harmony of the organization, within the department or within the specialized area. This closed culture fosters a corporate culture that excludes outsiders. In times of change and globalization, it is necessary to achieve open innovation by the fusion of heterogeneous technologies, fusion of technologies and markets, and integration across different industries. Cooperation and empathy with people who have completely different values and life styles beyond those of the divisions, specialty sections areas or companies are required. Nissan's CFT was an effective way to break down the previously closed cultures of the company.

If the disadvantage of closed cultures is overcome in BUD, all the employees can become a powerful force in achieving the reforms together. Without doing so, successful reform will not be possible.

BUD, which places importance on corporate growth, organizational harmony and cooperation from a long-term perspective, should be considered a strength of Japanese companies, while implementation of TDD is also important in an era of change.

\section{A lack of organizational ambition towards innovation}

Changing ways of thinking and methods of management in the face of intense environmental changes such as globalization and information-oriented society can bring innovation. The key for Japanese companies aiming for innovation is organizational ambition. In other words, it is whether firms can face risks with determination and ambition. Penetration and consolidation of this organizational ambition throughout the company is also a vital factor in innovation management. Fujifilm, which succeeded in structural reform, survived a big wave of change from analog to digital technology, because the company had a corporate cultural and organizational ambition that emphasized R\&D. Since its founding, it has always pursued innovation. As a result, it was possible to make a major shift from the photographic business to the medical business.

\section{Necessary actions in eras of change}

Structural reform should evolve constantly in eras of change. Organizations, therefore, need to take the following actions: 
- Keep up with the latest developments and trends.

- Analyze the causes of management crises.

- Propose concrete and practical solutions rather than abstract ideas.

- Have organizational management that motivates employees.

- Execute process-oriented problem solving.

As shown in the failure case of Sharp, Japanese companies often lack rational ways of thinking and methods and the staff organization does not sufficiently assist top management. Companies must think logically, put their ideas into practice, continue experiential feedback, and find new, better ways of solving problems.

The corporate responses to the management crises shown in Tables 1 and 2 may assist Japanese companies to adapt to this new management style.

\section{The need for a new employment system}

Elimination of the seniority system, which many consider a weakness of Japanese management, is essential to allow capable young people to play active roles in their organizations and to develop innovation. Ghosn presided over such a change of the seniority system through Nissan's reforms. Nagashima (2015) and Nakane (2015), who worked in European and American companies as Japanese managers, have insisted on the necessity of the urgent dissolution of the seniority system. Unfortunately, this problem remains.

The advantage of lifetime employment in Japanese firms is that employees do not have the anxiety of being dismissed and feel a sense of loyalty to the company. An employment system that can proactively exploit these strengths should be developed. On the other hand, under the lifetime employment system, there is an irrationality: young employees cannot fully demonstrate their abilities under incompetent bosses. Moreover, young employees with ability, who contribute a lot to the company, are usually on low wages. These inequalities must be eliminated. Japanese companies face a declining birthrate and an aging society. Greater employment of qualified elderly workers could help this situation. The result of utilization of elderly employees with high skill levels and rich experience would not only alleviate the labor shortage but would also help transfer these experiences and skills to young employees. These elderly workers also usually place emphasis on contributing to society through making use of their abilities rather than just making money. It seems that presently Japanese companies have insufficient systems in place to make use of these elderly employees.

\section{A proposal for a new Japanese management model}

The authors have stressed the importance of understanding that change is normal. To proactively respond to the change, it is necessary to incorporate a new culture into the traditional corporate culture, and in technological development, it is necessary to engage in open innovation as well as internal research. In addition to the pursuit of short-term profits, a long-term strategy for sustainable corporate growth is also 
necessary. It will also be necessary to integrate the role of top management with the utilization of employees and their abilities, which is one of the strengths of Japanese companies. Thus, the basic approach is to innovate to a hybrid type of management by combining different vectors. For this purpose, the role of top management will also be important. And, to clarify the direction management should take to external environmental change, it is necessary to take a bird's-eye view that systematically looks at all management possibilities.

It is necessary to build a corporate philosophy on the premise of constant change and to incorporate a balance between short-term and long-term strategies into the management policy. A balance between technology push (value creation) and market pull (value acquisition) is necessary. Companies then need to create a business model which pursues their management policy. It is necessary for top managers to demonstrate their leadership and to improve their problem-solving techniques in areas such as cause analysis of management crises, solution proposals, implementation of action plans and revisions plans as the results of feedback. Companies should be willing to face battle. To do this, top management needs a strong commitment to innovation and quick decision-making on business rebuilding. It also needs to create an improved staff organization which can quickly support top management decisionmaking. Eliminating the disadvantages of old style Japanese management such as the seniority system, and establishing a new personnel management system which fosters younger workers is also necessary. This would create a new corporate culture, break the closed nature of groups within the organization, and improve employee motivation. In addition, the ability of employees in Japanese companies is high, and topdown based on clear vision will increase employee motivation and productivity.

It is necessary to integrate corporate ethics and corporate sustainability from a long-term perspective into management strategy, design competitive advantages into the core technology and acquire state-of-the-art technical information into the technical strategy. The business strategy should include plans for the acquisition of new business where core technology can be utilized effectively. Indispensable for these strategies are the concepts of open innovation and globalization. It is important to pursue management strategies which uniquely suit the characteristics of the Japanese situation. This will be different from European and American models but should utilize some of their better features which can be integrated into the Japanese model. Japanese companies have many innovative technologies such as material, manufacturing, robot, railway and railway operating infrastructure, nursing care and medical, aquaculture and environmental preservation. It should be possible to build new businesses that integrates such innovative technologies and information technologies, with these innovative technologies as the cores of new business. The authors point out that it is important not to focus solely on manufacturing but also to concentrate on the creation of added value that combines both aspects of technology (value creation) and market (value acquisition). In developing products, systems and businesses it is necessary to reflect on the results of rapidly progressing technological innovation in a wide range of fields. Management in the twenty-first century requires open innovation to create value in global business.

The lack of profit-orientated attitude was one of the weak points in Japanese management. In order for a company to survive and be stable short-term profits 
from existing business are important. However, from a long-term point of view, companies need to invest in cultivating new business for future growth. It is important to skillfully balance these two aspects. Return on Equity (ROE) oriented management that pursues profits efficiently from existing businesses and returns them to investors is currently the mainstream in western countries. In contrast, Japanese companies, where the strength of shareholders and investors is weaker than those of Europe and the United States, can invest in their own future business profit through developing new technology and new business. However, Japanese companies need to establish management strategies that place even more emphasis on long-term strategies. From a long-term perspective, technological development requires not only open but also closed strategies.

The authors conclude that the management of Japanese companies requires a hybrid management of traditional Japanese management and modern management, and it is important to change this balance according to the situation of company.

\section{Concluding remarks}

Changes in the business environment require that Japanese companies change their management paradigms by changing their basic ways of thinking and their management methods. However, though many Japanese companies are fighting hard, it is difficult for them to find a path for these shifts, which involve a complicated mix of factors such as industrial characteristics, technological trends, the company's position in the market, corporate culture, management resources and management decision-making mechanisms. It is not easy, therefore, to find the right prescription.

Since the nature of structural reform and innovation differs for each industry or company, even those in the same field, there is no one effective prescription for all. Also, in eras of change, it is difficult to predict future changes. Top management, therefore, is often forced to make risky decisions in uncertain environments. Under these circumstances, it is necessary for companies to implement fundamental changes of attitude and decision-making methods that allow them to survive and grow, and to implement structural reform and innovation to replace stale ways of thinking and decision-making processes in the management and organization.

The authors hope that the proposed model will be useful for Japanese companies coping with restructure and innovation and will also help companies that work with Japanese companies to gain a deeper understanding of Japanese management style. Especially for Japanese technology companies, this model will be useful. In addition, the big social environment change by COVID-19 has a great impact on the market, but it is also an opportunity for technological development. The authors hope that Japanese companies will overcome this crisis through a sense of unity between management and employees.

Data availability All data are included in the manuscript.

\section{Declaration}

Conflict of interest The authors declare that they have no conflict of interest. 


\section{References}

Aslam F, Aimin W, Li M, Ur Rehman K (2020) Innovation in the era of IoT and industry 5.0: Absolute Innovation Management (AIM) framework. Information 11(2):124. https://doi.org/10.3390/ Info11020124

Barbieri P, Boffelli A, Elia S, Fratocchi L, Kalchschmidt M, Samson D (2020) What can we learn about reshoring after Covid-19? Oper Manag Res 13(3):131-136

Bhushan B (2009) Biomimetics: lessons from nature: an overview. Phil Trans R Soc A 367:14451486. https://doi.org/10.1098/rsta.2009.0011

Canhoto AI, Clear F (2020) Artificial intelligence and machine learning as business tools: a framework for diagnosing value destruction potential. Bus Horiz 63(2):183-193

Chesbrough HW (2013) Open Innovation: Implications for Japanese Innovation. Annual Report on Japanese Silicon Valley Innovation Forum 2013

Chesbrough HW (2014) Open Innovation: The Response of Japanese Firms - Report to NEDO -, Japan New Energy and Industrial Technology Development Organization, Tokyo

De Wit A, Shaw R, Djalante R (2020) An integrated approach to sustainable development, National Resilience, and COVID-19 responses: the case of Japan. Int J Disaster Risk Reduct 51:101808

Deutsch CH (2008) At Kodak, some old things are new again. The New York Times. May 2nd, 2008. https://www.nytimes.com/2008/05/02/technology/02kodak.html. Accessed 25 Dec 2020

Earley CP, Mosakowski E (2000) Creating hybrid team cultures: an empirical test of transnational team functioning. Acad Manag J 43(1):26-49

Economist (2012a) Sharper focus: how Fujifilm survived. January 18th of 2012, K.N.C., TOKYO. https:// www.economist.com/blogs/schumpeter/2012/01/how-fujifilm-survived Accessed 4 Feb 2018

Economist (2012b) Technological change: the last Kodak moment? January the 14th 2012, New York and Tokyo. http://www.economist.com/node/21542796 Accessed 4 Feb 2018

Endo T, Delbridge R, Morris J (2015) Does Japan still matter? Past tendencies and future opportunities in the study of Japanese firms. Int J Manag Rev 17(1):101-123

Foss NJ (2020) The impact of the Covid-19 pandemic on firms' organizational designs. J Manag Stud 58:270-274

Gantenbein P, Kind A, Volonté C (2019) Individualism and venture capital: a cross-country study. Manag Int Rev 59(5):741-777

Ghosn C (2002) Saving the business without losing the company. Harvard Business Review Diamond HBR, Boston, pp 40-49 (Translated in Japanese version by Nakagawa, H)

Hatou R (2013) Introduction to management strategy: from the birth of business administration until a new type of Japanese management. PHP Business-shinsho, Tokyo, p 206

Ikegami JJ, Maznevski M, Ota M (2017) Creating the asset of foreignness: Schrödingers cat and lessons from the Nissan revival. Cross Cult Strateg Manag. https://doi.org/10.1108/CCSM-12-2015-0194

IMD (International Institute for Management Development) (2020) IMD World Competitiveness online. https://worldcompetitiveness.imd.org/countryprofile/overview/JP. Accessed 25 Dec 2020

Innovation 100 Committee (2016) Whose job is corporate business innovation? Japan Innovation Network and Ministry of Economy, Trade and Industry of Japan. https://www.meti.go.jp/committee/ kenkyukai/sansei/keieisha_toushika/pdf/003_04_00.pdf. Accessed 25 Dec 2020 (in Japanese)

Kagono T (2012) Why Kodak went bankrupt and Fujifilm is doing well. PRESIDENT. http://president.jp/ articles/-/5806. Accessed 25 Dec 2020 (in Japanese)

Keizer A, Umemura M, Delbridge R, Morgan G (2012) Japanese Management 20 years on the Contemporary Relevance of Japanese Management Practices. The Advanced Institute of Management Research. https://www.research.manchester.ac.uk/portal/files/37901468/FULL_TEXT.PDF Accessed 25 Dec 2020

Komori S (2013) Management of the spirits, 1st edn. Toyokeizai-shinposya, Tokyo (in Japanese)

Kusaka Y, Hirasaka M (2011) A hybrid approach for management decision-making. Dokkyo Univ Stud Econ 90:17-33 (in Japanese)

Kusaka Y, Hirasaka M (2013) Product development processes for creating added value: using the process-oriented hybrid approach. Dokkyo Univ Stud Econ 92:27-40 (in Japanese)

Kusaka Y, Hirasaka M (2014a) Decision-making of product and business development under a complex situation using the hybrid approach. Dokkyo Univ Stud Econ 94:29-42 (in Japanese)

Kusaka Y, Hirasaka M (2014b) Finding a new way of Japanese technology management. Dokkyo Univ Stud Econ 94:43-64 (in Japanese) 
Kusaka Y, Hirasaka M (2016a) Management of paradigm shift in a changing era: learning from the cases of Kodak and Fujifilm. Dokkyo Univ Stud Econ 98:5-20 (in Japanese)

Kusaka Y, Hirasaka M (2016b) Management of paradigm shift in a changing era: learning from the cases of Nissan and Sharp. Dokkyo Univ Stud Econ 98:21-37 (in Japanese)

Maine J, Florin SE, Umans T (2020) Ambidextrous sustainability, organisational structure, and performance in hybrid organisations. Acad Manag Proc 1:11378

McGrath RG (2013) The end of competitive advantage: how to keep your strategy moving as fast as your business. Harvard Business Review Press, Boston

Min YK, Lee SG, Aoshima Y (2019) A comparative study on industrial spillover effects among Korea, China, the USA, Germany and Japan. Ind Manag Data Syst. https://doi.org/10.1108/ IMDS-05-2018-0215

Moon Jr PT (2019) Missed moments: Kodak's failure to define the consumer market for digital photography. History Theses 4 (State University of New York College at Buffalo) https://digitalcommons. buffalostate.edu/history_theses/48/ Accessed 25 Dec 2020

Morris J, Hassard J, Delbridge R, Endo T (2019) Understanding managerial work in the modern Japanese firm: the influence of new organizational forms and changing human resource management practices. Econ Ind Democr. https://doi.org/10.1177/0143831X19875785

Nagashima S (2015) A Japanese type of industry 4.0, 1st edn. Nikkei Publishing Inc., Tokyo (in Japanese)

Nakada Y (2015) Sharp: teachings from the liquid crystal business failure (in Japanese), 1st edn. Jitsumukyoiku-syuppan, Tokyo

Nakane S (2015) Manufacturing business management strategies in the era of IoT, 1st edn. Gentohsya, Tokyo (in Japanese)

NHK (Japan Broadcasting Corporation) (2005) Managers who changed Japan: Calros Gohn in Nissan Motor Co., 1st edn. NHK DVD the MessageII, Tokyo (in Japanese)

Nikkei Business (2015) An emergent feature: the truth of sharp crisis. Nikkei Business Publishing Inc., Tokyo (in Japanese, May 25th ed. 10-20)

Nisbett RE (2003) The geography of thought: how Asians and Westerners think differently...and Why, 1 st edn. Free Press, New York

Ogasawara Y, Shigehisa T (2009) A recommendation to Japanese type of innovation, 1st edn. Nikkei Inc., Tokyo (in Japanese)

Pan L, Zhou X (2018) CEO compensation in Japan: why so different from the United States? J Financ Quant Anal 53(5):2261-2292

Sharp Company (2015) Restructuring stable revenue structures through decisive realization of drastic management reforms (in Japanese). Sharp Mid-term Management Plan on 15 May 2015. Sharp Company, Tokyo

Shibata T, Baba Y, Kodama M, Suzuki J (2019a) Managing ambidextrous organizations for corporate transformation: a case study of Fujifilm. R\&D Manag 49(4):455-469

Shikata N, Goto S, Gemba K (2019b) Servitisation of manufacturing industry in Japan. Forum Sci Econ 7(3):19-30

Shimura Y (2009) Manufacturing in Japan: a cultural perspective. Q J Public Policy Manag 3:1-16 (in Japanese)

Song M, Montoya-Weiss MM (2001) The effect of perceived technological uncertainty on Japanese new product development. Acad Manag J 44(1):61-80

Takata H (2016) Effects of industry forces, market orientation, and marketing capabilities on business performance: an empirical analysis of Japanese manufacturers from 2009 to 2011. J Bus Res 69:5611-5619

Tohoku University Management Group (2008) Actions towards destructive technologies and re-definition of corporate domain: the case of behaviors of Fujifilm Company under the digitized camera industry (in Japanese). In: Harvad Business (eds) New ed. management: learning from cases. Yuhikaku Books, Tokyo

Tongur S, Engwall M (2014) The business model dilemma of technology shifts. Technovation 34(99):525-535

Wang W, Siau K (2019) Artificial intelligence, machine learning, automation, robotics, future of work and future of humanity: a review and research agenda. J Database Manag 30(1):61-79

Yoshino Y, Egawa M (2010) A Challenge toward regeneration by Nissan Motor Co. In: Harvard Business School (eds) Case Studies of Japanese Companies (in Japanese). HBS Japan Research Center, Tokyo, pp 33-67 